\title{
An Interoperability Architecture for Networked Service Delivery
}

\author{
Stephan Kassel ${ }^{1}$, Christian-Andreas Schumann ${ }^{1}$, Andreas Rutsch ${ }^{1}$, \\ and Thomas Reich ${ }^{2}$
}

${ }^{1}$ Westsächsische Hochschule Zwickau, Institute for Management and Information, PSF 201037, 08012 Zwickau, Germany

\{Stephan.Kassel, Christian.Schumann, Andreas.Rutsch\} @fh-zwickau.de

${ }^{2}$ Neustädter-Forum Thomas Reich, Am Lederwerk 1, 07806 Neustadt/ Orla, Germany

reich. thomas@web. de

\begin{abstract}
This paper describes a service architecture which is especially suited for networked enterprises to provide services cooperatively. The overall architecture is described as well as the service composition process. The architecture is evaluated from a business perspective and the advantages and disadvantages are discussed.
\end{abstract}

Keywords: Service interoperability, interoperability architecture, business service composition, negotiation of services, quality of services.

\section{Introduction}

Service industry is gaining more and more attention in the USA and the European Union. [1] There are mainly three reasons for this development. First of all, labor costs for production are too high in Europe and the USA to be competitive any longer when concentrating on basic production. Second, the role of services is growing even in industry, thus leading to an increasing share of product-accompanying services on the overall value of the product. This leads to growing revenues for the companies who are performing well in defining that kind of enriched product offering. Third, the average age of the population of most of the European countries is ever-growing, leading to customers who are less in need for new products, but far more in need for special services in the health sector, medical treatment, nursing and personal care as well as everyday services.

So the business is in a dramatic transformation, leading to new chances for enterprises which are performing well in delivering those services, but also to harder constraints for enterprises which are not able to master this transformation.

With a deeper look at the service industry, it is possible to differentiate between basic services, which can be performed without a special qualification (we can call them low-level services), and very sophisticated services which can only performed by specialists with a high qualification (hereafter called high-level services). In the low-level service market, there is a big competition with the main constituent of the price of the service. This leads to shrinking revenues for the companies providing those low-level services, and to a tendency of off-shoring those services (if possible) 
to low-salary regions of the world, where they could be performed with less costs for the service-providing companies and the customers of the services. In the high-level service market the competition is based on differentiation of the offering. This differentiation is achieved by the uniqueness of the service offering and/or the high quality of the service provisioned.

Especially these high-level services are becoming more and more complex, being constituted by a huge set of service primitives, which are combined in a special manner to provide the high-quality service offering specific for the customer.

Winners of this business are the enterprises who are able to provide these rich services to their customers. Competitive advantages can be achieved by building up networks of service providing specialists who are able to jointly deliver high-quality services. In this situation, technology is needed to help in the service composition, service qualification, and the service provisioning.

\section{State of the Art}

To achieve the goal of the paper, this section concentrates on the state of the art in the service composition, service provisioning, and service quality. The proposed architecture should solve the problems arising on these topics; therefore there is a concentration on the state of the art in the decision theory, helping to solve the problem of service composition, and on service interoperability, which helps on the service provisioning and the service quality.

\subsection{Service Composition}

The idea of combination of services out of basic service constituents is already widely used by service-oriented architectures (SOA) [2]. With SOA, it is possible to technically include services, which can be defined, provisioned, and billed at another place of the world. The services are usually provided on the Internet, by using special protocols to locate, and use service components. These service components consist mainly of software, but the basic SOA definition could easily be enhanced to other services which are not consisting of software alone. The composition of the services is mostly done by building business process models where the services, which should be used by some providers in the Internet, are explicitly named and some constraints on these services are defined, helping to identify the appropriate service on run-time of the business processes.

The service providers can be located anywhere in the world. The actual identification of the appropriate services at run-time is done by world-wide lookup in a repository of service descriptions, which are written in a formal kind of service pattern (WSDL) [3]. This mechanism is very useful for the composition of primitive basic services, but it totally lacks the ability to build up networks of corporations working together to provide first-class services on a high level to some common customers. The lookup of the services is mainly done by a service signature; there is little additional information on the service providers. So there is little information to help with the choice between different service providers. There is a need to use higher levels of support for the choice of the most appropriate service providers. This can be achieved 
by using decision aiding systems [4]. These kinds of systems are assisting in making rational decisions. They are not trying to automatically choose service providers. The decisions of choosing and combining services should have a simple yet powerful model based on some common economic methodologies. This provides a solution to the identification and combination problem of services. The decision aiding system should

- $\quad$ provide a negotiation aid on the business level,

- explicitly include business interoperability,

- $\quad$ provide a basic pricing model for the service constituents,

- show a simple interface to the customer shielding the complexity of the service provisioning from the customer, but at the same time provide a full choice including a rich set of services,

- model user requirements which can be helpful when there is a need for renegotiation of the services consumed in case of a necessary mediation,

- explicitly address interoperability.

\subsection{Service Provisioning}

To provide a complex set of services, there is a need to match the requirements of the customers to several service providing companies. This leads to an interoperability problem, because there is no common understanding on the definition of the services, the context of the services, and the way of providing the service to this special customer. There is already a wide set of literature in the area of interoperability (e.g. [4], [5], [6], or [7]), but most publications still concentrate on technical levels of interoperability. Only in the latest time, there are some first research efforts on service interoperability, which has a different focus than the (technical) definition of service-oriented architectures (SOA). SOA concentrates on low-level, automated, technical-oriented services. The business-oriented terms of service industries, on the contrary, are defining services as immaterial "products". This has to be understood well inside of the IT-industry. In the roadmap of interoperability research of the European Union [8] there is a distinction of the technical interoperability levels from the business level of interoperability.

There is some research done in the enterprise interoperability scientific community, which can be useful for the definition of high-quality service interoperability. The work on model-driven interoperability, like [9], [10] and [11], provides some opportunities for an enhancement to service interoperability. There are some models of service interoperability existing, (e.g. [12] and [13]), which are very useful as a fundamental basis to solve the choice and combination problem. However, these models are rather complicated and lack simplicity in the practical usage. Severe problems, which are typical for service interoperability, are discussed in [14].

\subsection{Service Quality}

There is some work done to define service quality for the context of service interoperability. Especially the work on SQFD [15] shows, how some common models of service quality [16] can be enhanced to be used in the context of different service providers and different service consumers. 
But there are some hard restrictions to these models, coming from a lack of common understanding on the nature of services at all. There are no common definitions of service standards, so the service providers and the service customers are individually defining their own model of the "ideal" service. This often leads to unsolved conflicts in provisioning of the services. The extent of the problem may be best seen by the statistics on failed software projects (a very special kind of services), which are talking about numbers of $24 \%$ failed and $44 \%$ challenged projects [17] leading to enormous economic losses.

There is a big need for pragmatic ways of solving these problems of service quality and resulting re-negotiations of the service goals and measures, which should be addressed in the architecture proposed by the author in the next section.

\section{Components of the Service Architecture}

The authors have proposed a business architecture for service interoperability [18]. The main components of this architecture are sketched in Figure 1. (For a complete description of the architecture, cf. [19]).

The highest level of the architecture consists of a set of business service classes, forming the service portfolio of the (networked) company. The customers of the service can choose from the different service classes, and are able to get individual service portfolios which are exactly suited to their needs.

In each business, there is a set of standard service classes, from which the customers are choosing. Especially high-level service providers are able to deliver a great variety of instatiations for those service classes. To provide a simple yet powerful way of presentation for the choice of the individual services, they are combined to decision trees, helping the customer to take a choice in a very limited time. In these decision trees, the services directly provided by the service company are listed near the services of the network partners. For the customer, the service portfolio is at that step of service choice transparent. There is a possibility that there are competitive services in this architecture, but there are clear rules defined, in which case which of these competitive services will be chosen. These rules are manifesting themselves in the decision trees. The task of the networked service company lies in the definition of the service classes, and the choice of the business partners in the service network and their responsibilities.

The composition of services is done on the third level of the service architecture, where the different services which are chosen, are combined by the combination of the service process models into some kind of skeleton service process.

In case of software services, these services can be easily provided by model transformation of the service processes to workflow models, which may be compiled to efficient code. In case of personal services, the workflows can be used to generate service provision orders to the people who are involved in the provision of the service.

The quality of the service is defined by the satisfaction of the customer with the service provisioning. There are a huge number of influencing factors when customer satisfaction is measured. Especially when the quality of complex services is evaluated, there are two big classes of these factors. The first class consists of the quality of 


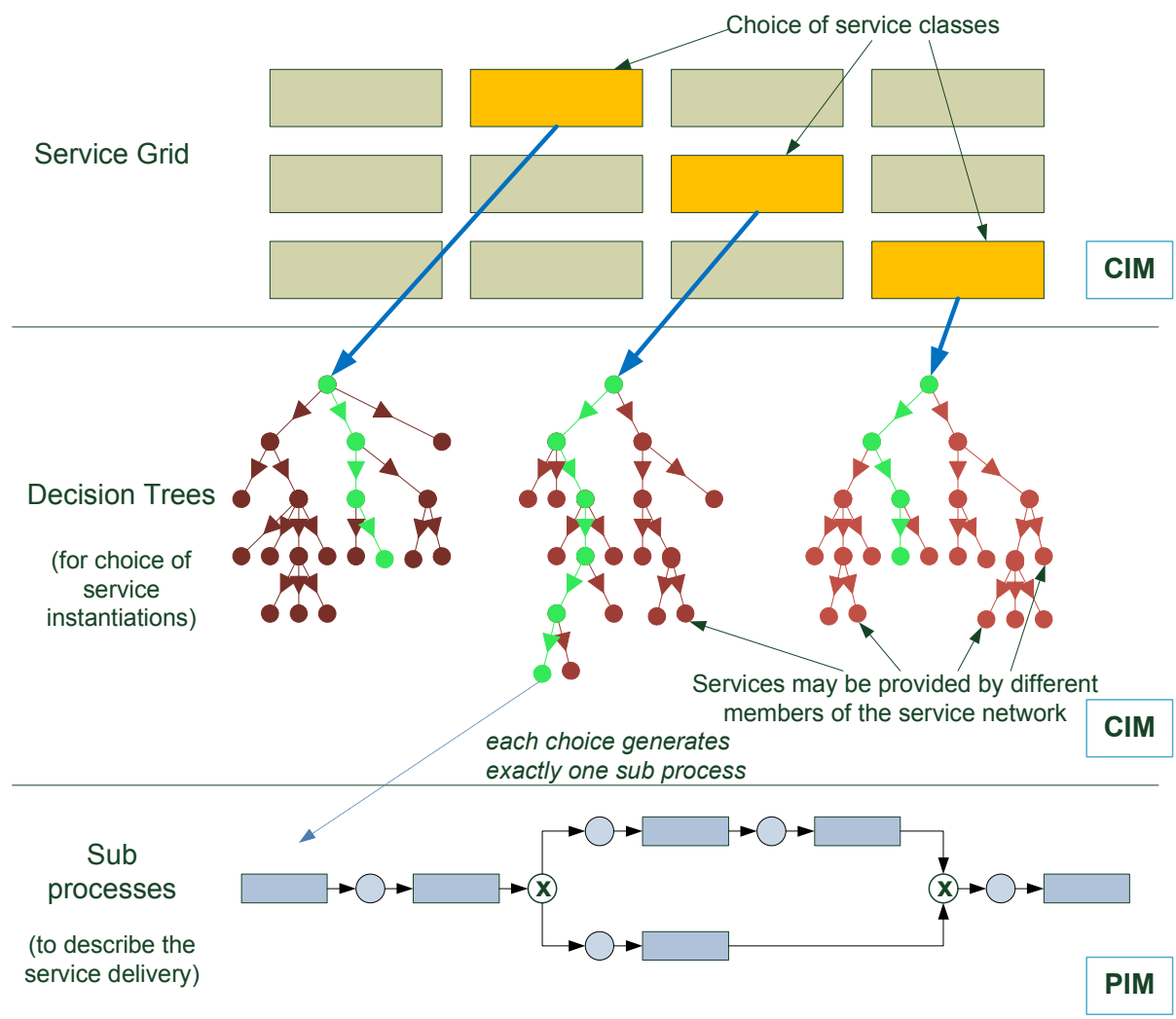

Fig. 1. The upper levels of the interoperability architecture for networked service delivery

the service components, which are mainly influenced by the choice of the right persons delivering the individual service, the choice of the right process steps and the pricing of the service which should be fair for the customer. There are additional constraints, like the timeliness of the service provision, which are influencing the evaluation of the individual service from the point of view of the customer. But there are other factors stemming from the complex service composition out of single services. They are mainly influenced by the composability of the service components. This means that the processes of the service components have to be seamlessly integrated. The customer is expecting that information he provides, is transferred along the overall service process, so the knowledge of the customer has to be provided from the service partners to each other. The customer does not want to explain his ideas more than once, he does not want to suffer from a distributed service provision, and he does not want to pay for transaction costs stemming from interoperability problems of the service-providing companies. The customer wants to have an impression of the services coming "from one hand", including a common timeline for all individual service components. 


\section{Discussion of the Service Architecture}

The proposed service architecture has some obvious advantages, but also some limitations, which are discussed in this section.

The advantages of the service architecture can be divided into advantages for the owner of the service architecture, the (networked) service providing company, and the advantages for the service recipient, namely the customer of the service company.

The networked service company is getting much help in the definition of the services. The services are modelled in a pragmatic way and on a very high level, leading to a high-level overview of the service offering. This overview helps in negotiations with prospective service partners, leading to clearer partner contracts and more integrated service portfolios. The architecture helps in identifying the different service partners and their responsibilities and opens up measures to minimize risk of being dependent from special partners by scattered partner offerings, leaving enough room for business relationships with competitive partner companies.

The architecture also defines clear rules for the networked service provisioning, by a fixed definition of the partitioning of business. Each partner is informed, in which cases his offering is chosen by the customers. This may increase satisfaction for the business partners (if they are getting revenues out of the cooperation).

The service customer has some advantages as well. The clear structure of the service components by the service classes, from which he can choose the appropriate services, leads to a greater transparency for the customer. He is informed on the service components, he can expect. The customer gets a clear description of his choice, which could be enhanced with fixed prices for the service components, if they are not too complex. This is leading to target pricing for the services, thus the customer can give some price constraints restricting the service choice for him.

And if there are problems with service quality, it is easier to divide the service components which are problematic from the point of view of the customer, and replace them by other service components, which have similar properties, and may be better suited to the customer. Due to the pricing model which is pricing the individual components, it is easier to compromise on compensation for the work already done by the service provider, and the time invested by the service customer. This leads to a solution-oriented discussion about the conflicts in the service provisioning, and following to a higher satisfaction of both the customer and the service provider.

The architecture still shows some open issues which are not addressed now. First of these, there is no explicit description of company politics. But these politics always plays an important role in reality. There are often partnerships in service provisioning with companies, which are interesting from strategical reasons like being a key to an important future customer, or having other partners themselves, which are interesting from the view of the service company building up the network. These political partnerships cannot be modelled in an adequate manner. Second, the company building up the decision trees, is dividing the market share on the service revenues from the customers. It is hard to find objective choice criteria for the decision trees, especially when building a network with competing partners with very similar service offerings. Third, the compatibility of the services is dependant on some standardization on the interface description for the individual service processes. But this leads to some 
common black-box views of services. In this area, there is still a great need for research to define these standard service repositories.

\section{Conclusion}

In this paper, an architecture is defined, which is suitable for service composition. The advantages are described, as well as the open issues which should be solved to help for becoming a standard architecture for service interoperability. The authors are convinced that this kind of standardization is needed for service industry, especially when enterprises are operating on a global market with a big competition in the delivery of services. The networking aspects of service delivery are relevant competitive factors for service companies, so they need robust, pragmatic approaches to define these networks and their own role as well as the role of their network partners.

\section{References}

1. OECD Stat Extracts, Online Database of the Organization for Economics Co-Operation and Development, http: / / stats . oecd.org/

2. Erl, T.: Service-oriented architecture: concepts, technology, and design. Prentice-Hall, Upper Saddle River (2006)

3. W3C, Web Services Description Language (WSDL) 1.1, http: / / www.w3.org/TR/wsdl.html

4. Tsoukiàs, A.: From decision theory to decision aiding methodology. European Journal of Operational Research 187, 138-161 (2008)

5. Doumeingts, G., Müller, J.P., Morel, G., Vallespier, B.: Enterprise Interoperability: New Challenges and Approaches. Springer, Berlin (2007)

6. Gonçalvez, J., Müller, J.P., Mertins, K., Zelm, M.: Enterprise Interoperability //: New Challenges and Approaches. Springer, London (2007)

7. Mertins, K., Ruggaber, R., Popplewell, K., Xu, X.: Enterprise Interoperability III: New Challenges and Industrial Approaches. Springer, London (2008)

8. Li, M.-S., Cabral, R., Doumeingts, G., Popplewell, K.: Enterprise Interoperability research roadmap (July 2006),

http://cordis.europa.eu/ist/ict-ent-net/ei-roadmap_en.htm

9. Girard, P., Doumeingts, G.: GRAI-Engineering: a method to model, design and run engineering design departments. International Journal of Computer Integrated Manufacturing 17(8), 716-732 (2004)

10. Blanc, S., Ducq, Y., Vallespir, B.: Evolution management towards interoperable supply chains using performance measurement. Computers in Industry 58(7), 720-732 (2007)

11. Mertins, K., Knothe, T., Jäkel, F.-W.: Interoperability - Network Systems for SMEs. In: [7], pp. 511-520

12. Protogeros, N., Tektonidis, D., Mavridis, A., Wills, C., Koumpis, A.: FUSE: A Framework to Support Services Unified Process. In: [7], pp. 209-220

13. Xu, X.F., Mo, T., Wang, Z.J.: SMDA: A Service Model Driven Architecture. In: [6], pp. 291-302

14. Wang, Z., Xu, X.: Ontology-based Service Component Model for Interoperability of Service Systems. In: [7], pp. 367-380 
15. Liu, S., Xu, X., Wang, Z.: A SQFD Approach for Service System Design Evaluation and Optimization. In: Proc. of I-ESA China 2009, pp. 23-27. IEEE Computer Society, Los Alamitos (2009)

16. Hauser, J.R., Clausing, D.: The House of Quality. Harvard Business Review, 63-73 (MayJune 1988)

17. The Standish Group: CHAOS Summary 2009, http: / / www. standishgroup.com/index.php

18. Kassel, S.: Design of Services as Interoperable Systems. In: van Sinderen, M., Johnson, P., Kutvonen, L. (eds.) Proc. of IWEI 2008, pp. 58-62. CTIT proceedings, Twente (2008)

19. Kassel, S.: An Architectural Approach for Service Interoperability. In: Proc. of I-ESA China 2009, pp. 212-218. IEEE Computer Society, Los Alamitos (2009) 